\title{
Effect of Twin Block Appliance on a Growing Patient - A Case Report
}

\author{
Mohammad Tariq, Sandhya Maheshwari, Sarah Asif*, Yumna Qamar and Shubhra Pathak \\ Department of Orthodontics and Dentofacial Orthopedics, Aligarh Muslim University, India
}

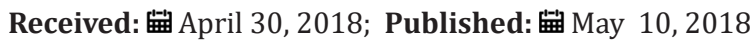

*Corresponding author: Sarah Asi, Department of Orthodontics and Dentofacial Orthopedics, Dr. Z. A. Dental College, Aligarh Muslim University, Aligarh, Uttar Pradesh, India

\begin{abstract}
Twin block appliance is very effective in a growing patient. The successful use of this appliance in the treatment of skeletal Class II malocclusion is based upon factors such as; age of patient, compliance of the patient and other case selection criteria. This case report includes a 14-year-old boy who was treated with twin block appliance. If treated timely, growth modification and orthopedic effects with this appliance can be achieved in a growing individual. This appliance is very successful in a patient with retruded mandible and well aligned arches in whom VTO is positive. This brings the mandible forward and improves the profile immediately.
\end{abstract}

Keywords: Twin block appliance; Growth modification; Myofunctional appliance; bite jumping

Abbreviations: VTO-Visual Treatment Objective

\section{Introduction}

Class II malocclusion is one of the most common problems around the globe affecting around one-third of the patients who come for orthodontic treatment [1-4]. According to McNamara, mandibular retrusion is the most common characteristic of this malocclusion [1-5]. Functional appliances are the appliances which bring about skeletal and dental corrections in these Class II patients with retruded mandible by utilizing force from the surrounding musculature. They were introduced long back and are now popularly used to correct Class II malocclusion in growing patients. In 1982, Clark [6] described the twin block appliance. In United Kingdom, since then it has been continuously used in clinical practice [7]. A lot of evidences have proved that it is one of the most successful appliance used for the correction of skeletal class II patients which can be used in any kind of pattern i.e. either hypo divergent, normodivergent or hyper divergent pattern with slight modifications to the appliance design.

The amount of mandibular advancement in twin block construction varies from patient to patient. In case of limited over jet, bite can be registered by placing incisors in an edge to edge relation while in case of large over jet bite is usually registered 2-3 times by advancing the mandible gradually, which according to many authors brings about greater orthopedic changes. Following is a case report of a 14 year old boy with normodivergent growth pattern, treated with twin block appliance for correction in both sagittal and vertical planes.

\section{Case Report}

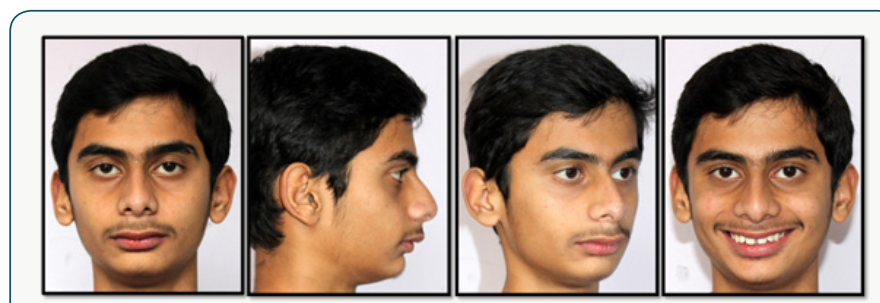

Figure 1: Pretreatment facial Photographs.

A 14 year old boy reported to the department with the chief complaint of forwardly placed upper front teeth and a non pleasing smile. Extra oral examination revealed that the patient had an apparently symmetrical face with a convex profile, competent lips, deep mento-labial sulcus with receded chin (Figure 1). Intraoral features showed a Class II Molar relation on left side and Endon molar relation on right side with Class II Canine relationship bilaterally, over jet of $9 \mathrm{~mm}$, overbite of $90 \%$ and maxillary mid 
line and mandibular midline in concordance with the facial midline and with each other (Figure 2). Orthopantomogram of the patient revealed a permanent dentition stage with 3rd molar buds seen in all the quadrants (Figure 3).

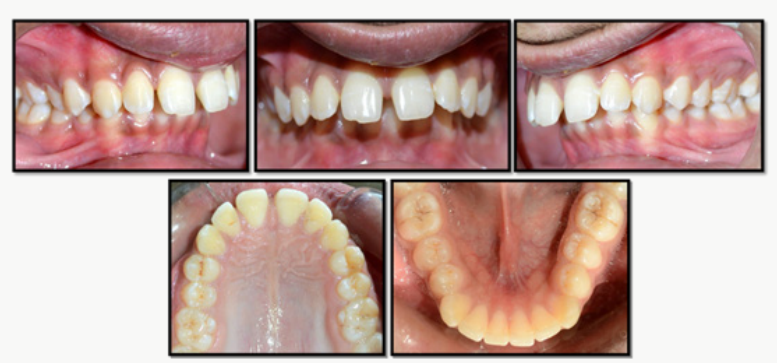

Figure 2: Pretreatment intraoral Photographs.

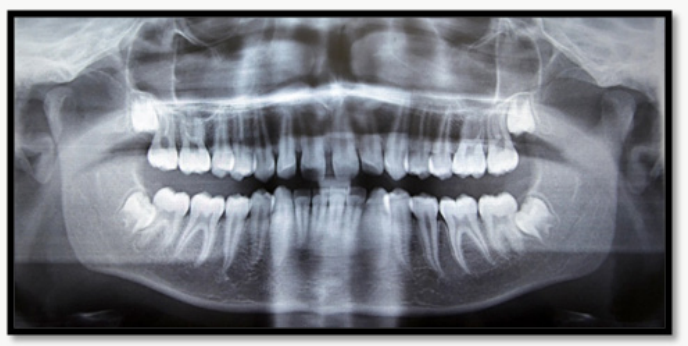

Figure 3: Pretreatment OPG.

Cephalometricanalysis (Figure 4) confirmed the case as Class II division 1 on a skeletal Class II base with mandibular deficiency along with ANB of $9^{\circ}$ and Wits of $8 \mathrm{~mm}$ (Figure $4 \mathrm{a}$ ). Skeletal values confirmed a normally positioned maxilla with retruded mandible in relation to cranium with a normodivergent growth pattern shown by Frankfurt-mandibular plane angle as $21^{\circ}$ (Figure $4 \mathrm{~b}$ ). Dento-alveolar findings showed proclined and protruded maxillary anterior and normally positioned mandibular incisors (Figure 4c). Cast analysis suggested a discrepancy of $3 \mathrm{~mm}$ in maxillary arch and $2.6 \mathrm{~mm}$ in the mandibular arch. Cephalogram (Figure 3) indicated that he was at the peak of his pubertal growth spurt (CVMI-IV) with a considerable amount of growth remaining. The patient also had a positive visual treatment objective (VTO) which also favored the use of mandibular advancement using the twin block appliance.

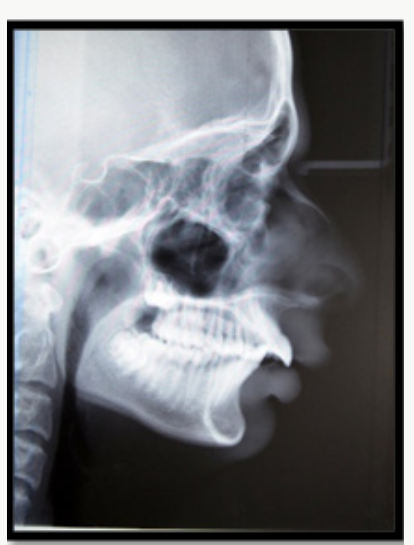

Figure 4: Pretreatment Ceph.

\begin{tabular}{|c|c|c|}
\hline & pre & $\begin{array}{c}\text { Post twin } \\
\text { block }\end{array}$ \\
\hline SNA & $85^{\circ}$ & $84^{\circ}$ \\
\hline SNB & $76^{\circ}$ & $79^{\circ}$ \\
\hline $\begin{array}{c}\text { ANB } \\
\left(3.12^{\circ} \pm 1.8^{\circ}\right)\end{array}$ & 9 & $5^{\circ}$ \\
\hline $\begin{array}{c}\text { Wits } \\
(-0.01 \mathrm{~mm})\end{array}$ & $8 \mathrm{~mm}$ & $4.8 \mathrm{~mm}$ \\
\hline FMA $\left(23.83 \pm 2^{\circ}\right)$ & $21^{\circ}$ & $21^{\circ}$ \\
\hline SN-MP $\left(32-35^{\circ}\right)$ & $30^{\circ}$ & $30^{\circ}$ \\
\hline
\end{tabular}

\begin{tabular}{|c|c|c|}
\hline $\begin{array}{c}\text { Mx 1 to A-Pg: } \\
6.74 \pm 1.3 \mathrm{~mm}\end{array}$ & $10 \mathrm{~mm}$ & 10 \\
\hline $\begin{array}{c}\text { Mx 1 to NA: } \\
4.92 \pm 2.05 \mathrm{~mm}\end{array}$ & $9 \mathrm{~mm}$ & 8.5 \\
\hline $\begin{array}{c}\text { Mx 1 to NA: } \\
24.02 \pm 5.82^{\circ}\end{array}$ & $38^{\circ}$ & $32^{\circ}$ \\
\hline $\begin{array}{c}\text { Mx 1 to Palatal Plane } \\
\left(71^{\circ}\right)\end{array}$ & $53^{\circ}$ & $59^{\circ}$ \\
\hline Figure 4b: Growth pattern. & \\
\hline
\end{tabular}

\begin{tabular}{|c|c|c|}
\hline Md 1 to A-Pg $(-2 \mathrm{~mm}$ to $2 \mathrm{~mm})$ & $1.5 \mathrm{~mm}$ & $1.5 \mathrm{~mm}$ \\
\hline Md 1 to NB $(6 \pm 1.7 \mathrm{~mm})$ & $7 \mathrm{~mm}$ & $7 \mathrm{~mm}$ \\
\hline Md 1 to NB $\left(27 \pm 4.3^{\circ}\right)$ & $25^{\circ}$ & $26^{\circ}$ \\
\hline IMPA & $99^{\circ}$ & $101^{\circ}$ \\
\hline Inter-incisor Angle $\left(123^{\circ}\right)$ & $113^{\circ}$ & $116^{\circ}$ \\
\hline
\end{tabular}

Figure 4c: Dental parameters.

\section{Treatment Objectives}

a. Achieving Class I molar \& canine relationship on both side.

b. Reduction of profile convexity and achieving optimum soft tissue balance.

c. Achievement of normal over jet and overbite.

d. Leveling and alignment of arches.

e. Long term retention.

\section{Treatment plan}

As the patient had skeletal and dental Class II relationship in growing phase, a two phase treatment was planned.

Phase I- Growth modification using functional appliance (twin block). 
Phase II- Fixed orthodontic mechanotherapy for final detailing of occlusion.

\section{Treatment progress}

Bite registration was done with a forwardly placed mandible and twin block was fabricated for the patient (Figure 5). Patient was asked to wear the appliance for 24 hours a day and after a period of 6 months, significant improvement was noted in the profile of the patient with correction in molar and canine relation as well as the over jet and overbite (Figure 6a, 6b and 7). This active phase of growth was followed by a retentive phase where the patient was given a removable reverse inclined plate to retain the correction obtained.

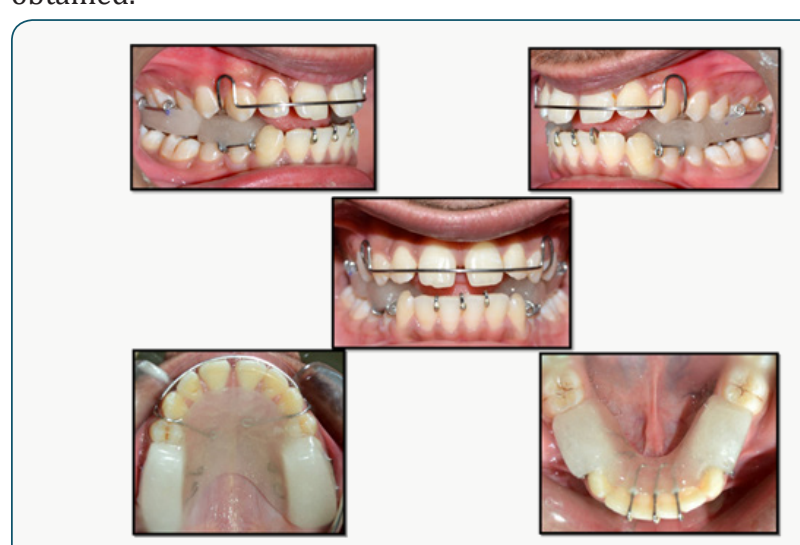

Figure 5: Intraoral photographs withTwin block appliance.

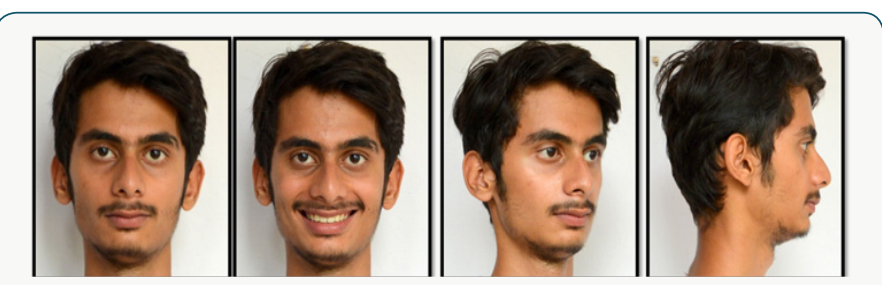

Figure 6a: Post twin block facial photograph.

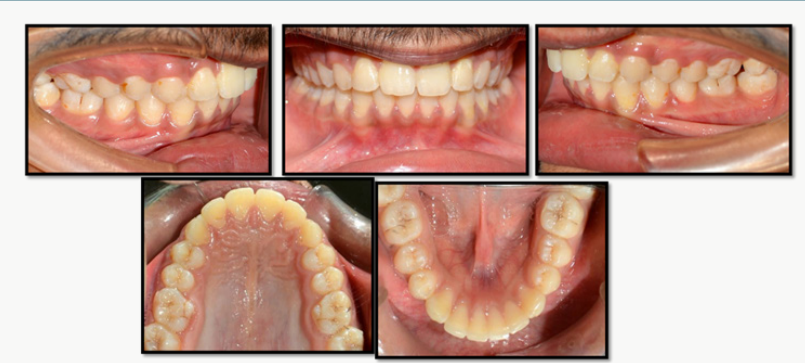

Figure 6b: Post treatment intraoral photographs.

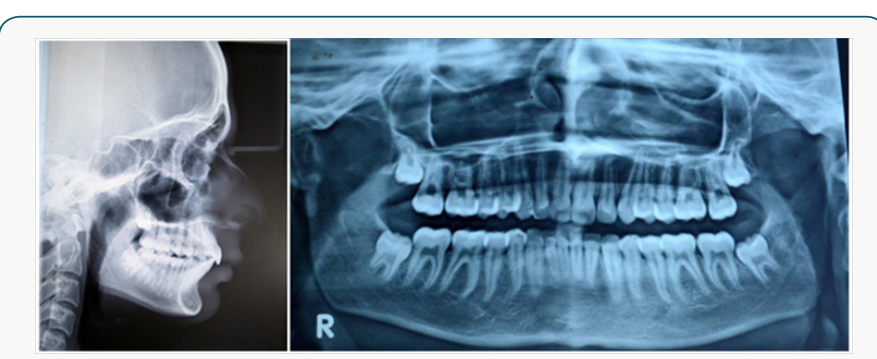

Figure 6c: Post treatment cephalogram and OPG.

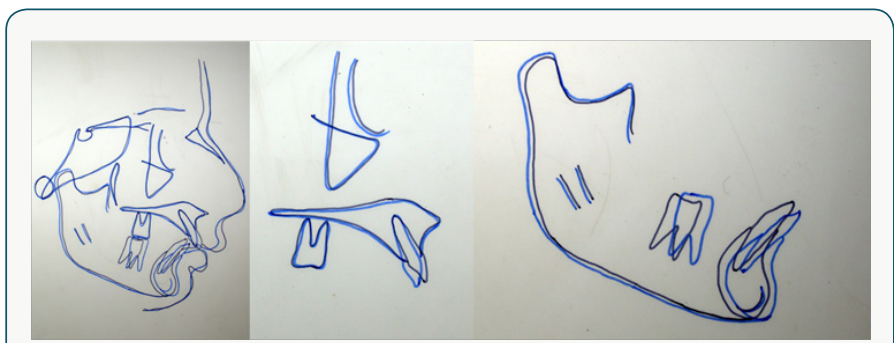

Figure 7: Superimposition of pretreatment and post treatment radiographs.

Superimposition at cranial base showed mesialization of mandible with retraction of upper lip. Remodeling at B point was visible. Superimposition at maxilla showed retrusion of maxillary incisors with no change at the molars. Superimposition of mandible showed mesialisation of lower molars with increase in proclination of lower incisors.

\section{Discussion}

Class II malocclusion can have a skeletal component, a dental component or a combination of both. Skeletally it may result either due to maxillary prognathism, mandibular retrognathism or their combination [8]. Therefore, identifying and understanding the proper etiology becomes really important for a proper diagnosis and finally to make a proper and effective treatment plan that may help in achieving the desired results.

Twin block is a functional appliance that is used in growing patients with mandibular retrognathism to reposition mandible in a forward position. It utilizes the surrounding neuromuscular forces to bring about orthopedic and orthodontic changes thereby causing mandibular displacement. The main advantage of twin block is that it is esthetic and comfortable which allows the patient to wear it for 24 hours thus bringing about the changes at a faster rate. There have been several studies to document the ability of twin block to produce significant skeletal as well a dentoalveolar changes, which in combination correct Class II malocclusion. Here, comparison of pre-treatment and post-twin block treatment lateral cephalogram showed an increase in SNB by $3^{\circ}$. ANB angle reduced up to $4^{\circ}$. Inclination of maxillary incisors also got corrected and length of the mandible increased by $1.7 \mathrm{~mm}$. The values of selected parameters before and after functional appliance therapy are shown in Figure $4 a-c$.

\section{Conclusion}

Functional appliance therapy is an effective way of treating skeletal Class II malocclusion due to mandibular retrusion via growth modification, however its effect depends upon patient compliance and case selection. Out of all the functional appliances, twin block, by far is one of the most popular functional appliances used and its use during growing phase with good patient cooperation can produce more of skeletal effects along with some dental effects. 


\section{References}

1. Prasad V Bond, Veerendra V Kerudi, Neeraj Patil, Siddhesh G Dolas, Harshal A Patil (2015) Treatment of Skeletal Class II Malocclusion with Twin-block. Journal of Applied Dental and Medical Sciences 1(3).

2. Proffit WR, Fields HW, Moray LJ (1998) Prevalence of malocclusion and orthodontic treatment need in the United States: estimates from the NHANES III survey. Int J Adult Orthodon Orthognath Surg 13(2): 97-106.

3. Gelgor IE, Karaman AI, Ercan E (2007) Prevalence of malocclusion among adolescents in central Anatolia. Eur J Dent 1(3): 125-131.

4. Celikoglu M, Akpinar S, Yavuz I (2010) The pattern of malocclusion in a sample of orthodontic patients from Turkey. Med Oral Patol Oral Cir Bucal 15(5): e791-e796.

\section{(C) \\ This work is licensed under Creative Commons Attribution 4.0 License}

To Submit Your Article Click Here:

Submit Article

DOI: $10.32474 /$ IPDOAJ.2018.01.000117
5. McNamara JA (1981) Components of Class II malocclusion in children 8-10 years of age. Angle orthod 51(3): 177-202.

6. Clark WJ (1988) The Twin Block technique. A functional orthopaedic appliance system. Am J Orthod Dentofac Orthop 93(1): 1-18.

7. Mills JR (1991) The effect of functional appliances on the skeletal pattern. Br J Orthod 18(4): 267-275.

8. Arici S, Akan H, Yakubov K, Arici N (2008) Effects of fixed functional appliance treatment on the temporomandibular joint. Am J Orthod Dentofacial Orthop 133(6): 809-814.

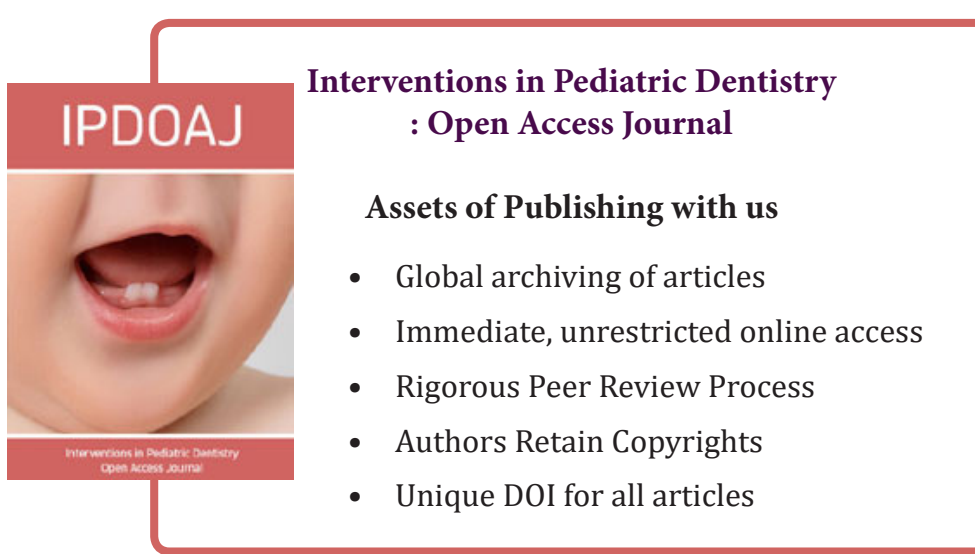

